\title{
Auditory evoked brain responses from the parakeet: Intensity functions
}

\author{
ROBERT J. DOOLING, JAMES K. WALSH, and DONALD I. TEPAS \\ Saint Louis University, 221 North Grand Boulevard, Saint Louis, Missouri 63103
}

\begin{abstract}
Averaged auditory evoked brain responses were collected from the skulls of unanesthetized parakeets. These responses were collected at eight intensities of a $1,000-\mathrm{Hz}$ tone. The waveform of the evoked response was highly consistent across birds, with a major positive deflection occurring at about $20 \mathrm{msec}$ after tone onset, followed by a negative deflection at about $40 \mathrm{msec}$ and a second positive deflection at about $100 \mathrm{msec}$. Over the intensity range examined, there is a log-linear relation between the intensity of the stimulating tone and the size of the evoked response. Threshold estimates obtained from this evoked response data compare favorably with the behavioral threshold at $1,000 \mathrm{~Hz}$ for the parakeet.
\end{abstract}

The relation between the averaged evoked brain response and the intensity of the auditory stimulus has been extensively studied, particularly in the human (Davis, Bowers, \& Hirsh, 1968; Rothman, 1970; Tepas, Boxerman, \& Anch, 1972) and other mammals (Henderson, Onishi, Eldredge, \& Davis, 1969; Rothenberg \& Davis, 1967). While little is known about this relation in birds, the response of birds to auditory stimulation has been examined by a number of psychophysical (Dooling, Mulligan, \& Miller, 1971; Dooling \& Saunders, 1975) and electrophysiological (Biederman-Thorson, 1970a, b; Harman \& Phillips, 1967; Harrison \& Furumoto, 1971; Saunders, Gates, \& Coles, 1974) studies. The electrophysiological investigations of auditory function in birds have involved single-unit or gross recordings from various levels of the auditory pathway in anesthetized preparations. Anesthesia has long been known to affect both visual and auditory evoked responses in mammals, and this effect has recently been demonstrated for the visual evoked response in the pigeon (Samson \& Lavine, 1972). Since the avian auditory system, both peripherally and centrally, is strikingly different from the mammalian auditory system (Boord, 1969; Karten, 1967, 1968; Schwartzkopff, 1968, 1973a), and since we know of no auditory evoked response data on unanesthetized birds recorded from extracranial electrodes, we felt it of interest to examine the relation between stimulus intensity and the averaged evoked response in unanesthetized parakeets.

\section{METHOD}

\section{Subjects}

The subjects were four male parakeets (about 6 months old) obtained from commercial dealers. Each subject was surgically prepared with a monopolar recording electrode assembly under a light dose of Nembutal $(1.5 \mathrm{mg} / \mathrm{kg})$. The essentials of this

Requests for reprints should be addressed to Robert $\mathrm{J}$ Dooling, The Rockefeller University, Field Research Center, Tyrrel Road, Millbrook, New York 12545. procedure have been reported previously (Dooling \& Walsh, 1974). In short, the skin covering the parakeet's skull is completely removed and an inverted steel-wire nail (head diameter approximately $2 \mathrm{~mm}$ ) is cemented to the surface of the skull with dental acrylic at a position approximately overlying "Field L" in the striatum (Ookawa \& Gotoh, 1965; Schwartzkopff, 1973a). Two small shallow holes were drilled in the skull to the left and right of midline as close as possible to the cere or nasal area. The skull is somewhat thicker here, minimizing the possibility of entering the brain cavity. In addition, this portion of the skull does not directly overlie the brain. A length of stainless steel straight pin, $.75 \mathrm{~mm}$ in diam and about $10 \mathrm{~mm}$ long, was gently inserted into each hole and cemented to the skull with dental acrylic along with the inverted wire nail. The two straight pins served as ground and reference electrodes. Resistance between electrodes was usually on the order of 10-20 KOhms. The three leads from the recording cable were spot soldered to the electrodes prior to placing the bird in the test chamber.

\section{Apparatus}

Auditory stimuli were generated by the modular system described by Tepas et al. (1972). With this system, 1-k-Hz tone bursts, $20 \mathrm{msec}$ in duration, were produced, having rise/fall times of $5 \mathrm{msec}$. The output of the audiometer was led to a 4-in. KLH speaker (Model 125), mounted in a small enclosure in a sound-deadened chamber. A series of Grason-Stadler 1200 electronic timers and pulse generators were used to present these tone bursts at a rate of $1 / 320 \mathrm{msec}$ and also trigger a DEC Lab-8 computer system.

The sound-deadened cylindrical chamber consisted of a heavy steel container lined with fiberglass and cotton approximately $20 \mathrm{~cm}$ thick on the sides and $30 \mathrm{~cm}$ thick on the bottom (internal dimensions were $50 \mathrm{~cm}$ diam $\times 60 \mathrm{~cm}$ deep). The KLH speaker enclosure was bolted to the inside of a 3/4-in.-thick plywood lid and surrounded by sound-absorbing material. A small wire cage, $10 \mathrm{~cm}$ high and $10 \mathrm{~cm}$ in diam, containing a single wooden perch, was affixed to the fiberglass-padded floor of the sound-deadened chamber such that when the lid was in place, the KLH speaker was $37 \mathrm{~cm}$ from the bird's head. The ambient noise level (measured in 1/3-octave bands) in this sound-deadened chamber was less than $20 \mathrm{~dB}$ SPL at frequencies above $200 \mathrm{~Hz}$. During recording, this chamber was placed in an electrically shielded experimental room on foam rubber pads $10 \mathrm{~cm}$ thick. Calibration of the sound field for steady state tones within the wire cage was performed by placing a $B$ \& $K \frac{1}{2}-$-in. microphone in the approximate position of the parakeet's head. 
The EEG was recorded from the inverted wire nail and referred to the left stainless steel pin. The right stainless steel pin served as the ground electrode. The EEG potentials were amplified by a P5A ac preamplifier of a Grass Model 7 polygraph and distributed to an AX08 analog input of the Lab-8 computer system. The bandpass characteristics of the amplifiers were set to $.15-500 \mathrm{~Hz}$.

Averaged evoked brain responses were computed by the Digital Equipment Corporation Lab-8 computer system using the Advanced Averager Program (DEC-LB-U18C-PB). Computations were made at 200 time points distributed over a 200 -msec analysis time. The averaged evoked responses we report are the sums of the EEG responses to 1,000 tone bursts. These were collected in four separate averages with each average consisting of the response to 250 stimulus presentations.

\section{Procedure}

Each bird was tested in four blocks during a single session. During each block, 250 responses to each of eight intensity levels were obtained. Intensity was varied in 5-dB steps over a $40-\mathrm{dB}$ range from $55 \mathrm{~dB} \mathrm{SPL}$ to $90 \mathrm{~dB}$ SPL (re $20 \mathrm{microN} / \mathrm{m}^{2}$ ). The order of presentation of these intensities was randomly varied within a block and a different random sequence was used for each block. Thus, each of the eight stimulus intensities was presented to each bird 250 times in each of the four experimental blocks for a total of 1,000 stimulus presentations at each intensity for the entire session.

The birds were run during the evening hours. At the beginning of the session, the bird was placed in the testing chamber and his EEG monitored until the recording was relatively artifact free. This usually required from 1 to $2 \mathrm{~h}$ in the dark. Once the subject was sitting quietly in the test chamber, as evidenced by visual examination of the EEG, the stimulus was turned on, and averaging was begun. In general, once the bird became quiet, he

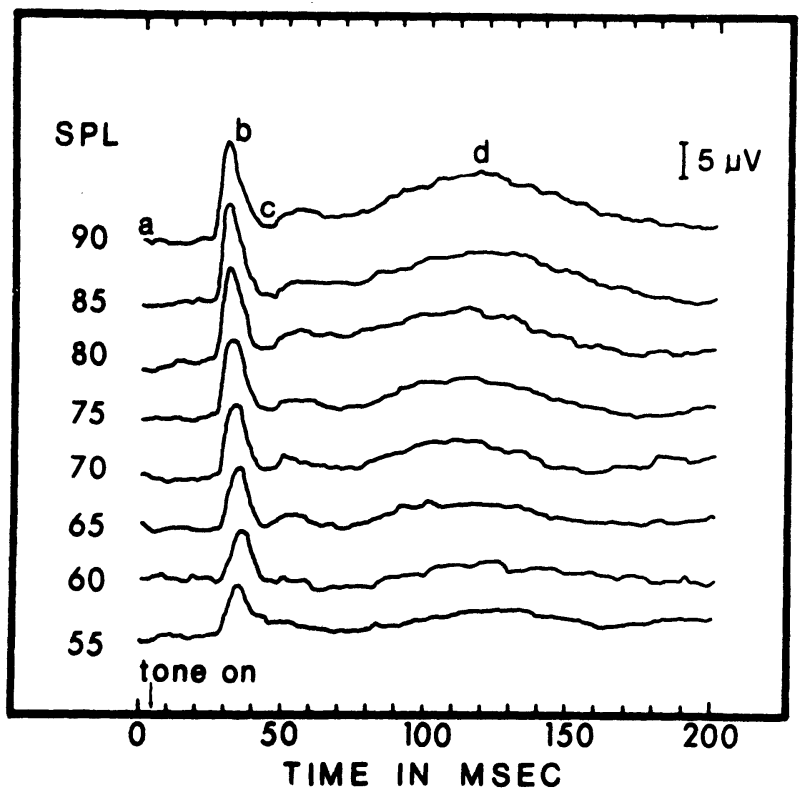

Figure 1. A complete set of pooled waveforms for a single bird (LB). Each waveform is the result of pooling punch paper tapes across the four blocks. A single waveform is the result of 1,000 stimulus presentations ( $250 \times 4$ blocks). The major features of these waveforms are labeled $a, b, c$, and $d$ An upward deflection means the recording electrode is positive with respect to the reference. Thus, $b-c$ might also be called $P_{1}-N_{1}$. Sound pressure level is in decibels (dB) re $20 \mathrm{microN} / \mathrm{m}^{2}$. remained so throughout the night with only occasional bursts of muscle activity evident in the EEG record. In the event that the EEG record indicated excessive movement or muscle activity, the experimenter could either momentarily stop averaging or mark this trial as "noisy" and rerun it at the end of the block. Both strategies were employed but used sparingly (three to five times per night).

Averaged evoked brain responses were computed in real time during the trials, and the resulting averages were punched out on paper tape for later analysis. At the end of each block of trials, a 100-msec square wave output of a Grass SD5 stimulator reduced to $10 \mathrm{microV}$ was summed to calibrate the evoked response measurements. This calibration signal was averaged in a manner identical to that used for the bird's EEG. Whenever feasible, the intertrial interval was kept constant at $90 \mathrm{sec}$. During this interval, the experimenter punched out the average from the previous trial and reset the attenuators for the next trial. After the bird had completed four blocks, the punch paper tapes were pooled across blocks for each intensity using the APE Program (Tepas, Kress, \& Klingaman, 1975). This procedure resulted in an " $N$ " of 1,000 for each bird at each sound pressure level.

\section{RESULTS}

The averaged evoked brain response waveforms for a single bird (LB) are shown in Figure 1. The major features of these waveforms are labeled alphabetically in order of occurrence using the nomenclature system of Tepas (1974). These features are evident at all stimulus levels. All birds gave responses highly similar to these both in amplitude and latency. Measurements were made on all waveforms in the following way. A baseline measure $a$ was defined as the mean value of the first $5 \mathrm{msec}$ of each waveform preceding tone onset. From a Teletype printout of each waveform $(n=1,000)$, the amplitude measures $a$ to $b, b$ to $c$, and $c$ to $d$, were computed along with the latencies to peaks $b, c$, and $d$. The deflection, $b$, was defined as the highest digitized value occurring between 10 and $30 \mathrm{msec}$ following tone onset. Likewise, $c$ and $d$ were defined as the lowest and highest values occurring between 20 and $90 \mathrm{msec}$ and 70 and $200 \mathrm{msec}$ following tone onset, respectively. This operation has previously been described in detail (Tepas, Kress, and Klingaman, 1975).

Figure 2 shows linear regression lines fitted to the data points by the least squares method for all three amplitude measures for a single bird (LB). Correlation coefficients for these amplitude measures show that for all components, the relation between evoked response amplitude and the intensity of the stimulating tone can be described quite adequately by a straight line over the intensity range examined. Similarly, the mean data points for all four birds for each measure are shown in Figure 3 along with regression lines. For descriptive purposes, the correlation coefficients and slope values for each regression line are also shown $(p \leqslant .001)$. The correlation coefficients for the individual birds for each component are shown in Table 1. The slopes of the regression lines for individual birds are shown in Table 2. 


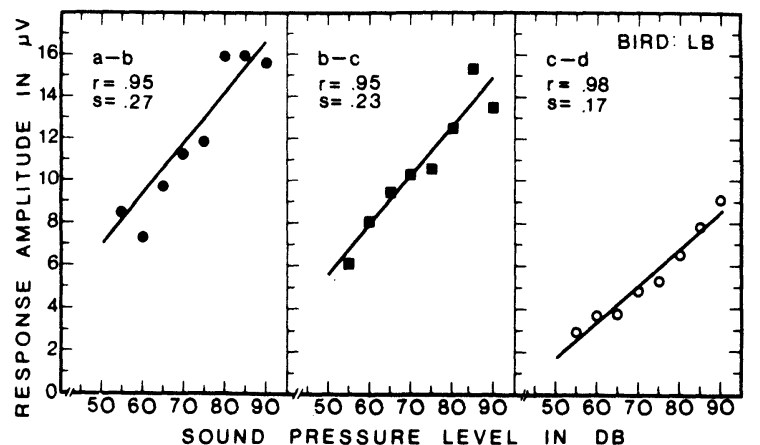

Figure 2. Amplitude-intensity functions for a single bird (LB). Each data point represents 1,000 stimulus presentations for a particular intensity. Sound pressure level is in decibels (dB) re $20 \mathrm{microN} / \mathrm{m}^{2}$.

Examination of Table 2 indicates the $c-d$ measure gave, in general, shallower slopes than did measure $a-b$ or $b-c$. Furthermore, in all but one bird, the slope of the regression line for measure $b-c$ was the steepest of the three slopes. Thus, the slopes for the regression lines obtained from pooled data for each measure are also a good reflection of the rank ordering of the slope values across measures for individual birds.

The latency to the major components $b, c$, and $d$ was also measured. Unlike amplitude data, however, latency measures were not as highly correlated with sound pressure level. In general, latency to each of the components was negatively related to sound pressure level. The correlation coefficients for pooled data for components $b, c$, and $d$ were: $-.899,-.275$, and -.508 , respectively. Thus, only the latency to the first positive peak (b) showed a significant correlation $(\mathrm{p}<.01)$.

The data for each bird was collected in only a single evening session comprised of four blocks, and the entire session was usually completed in 4 to $6 \mathrm{~h}$. During this time, we observed fluctuations in the EEG which sug. gested changes in the sleep-wakefulness of our parakeets. Since these fluctuations were similar to those described by Van Twyver and Allison (1972) for the sleeping pigeon, it appears that our parakeet evoked response data was collected across sleep stages. This fact, plus the long time elapsed between Block 1 and Block 4 and the possibility of a shift in sensitivity over the 4 to $6 \mathrm{~h}$ of nearly constant auditory stimulation, prompted us to look for differences between those evoked responses collected at the beginning of the evening (Block 1) and those collected at the end of the evening (Block 4).

First, the evoked brain responses collected in Block 1 for each bird were collapsed across intensities resulting in a single waveform for each bird. A similar procedure was applied to those responses collected in Block 4, and the amplitude of each response was referred to the appropriate calibration pulse for that block of trials. The amplitude measures for individual birds are shown in Table 3, along with the mean, standard deviation, and $\mathrm{t}$ ratio between those responses collected in Block 1 and those collected in Block 4. For all components, a t test between the mean of Block 1 and the mean of Block 4 shows no significant difference in size between evoked responses collected at the beginning of the evening and those collected at the end of the evening.

It may still be argued that the slope of the function relating amplitude of the evoked response to stimulus intensity may vary significantly from Block 1 to Block 4. Therefore, mean data points were obtained for all four birds for each component from Block 1 and

Table 1

Correlation Coefficients Associated With Amplitude-Intensity Functions for Each Bird

\begin{tabular}{|c|c|c|c|}
\hline \multirow[b]{2}{*}{ Bird } & \multicolumn{3}{|c|}{ Evoked Response Measure } \\
\hline & $a-b$ & $\mathrm{~b}-\mathrm{c}$ & $c-d$ \\
\hline $\mathrm{Y}$ & $.89 *$ & $.80^{*}$ & $.95^{*}$ \\
\hline B & $.98 * *$ & $.98 * *$ & .65 \\
\hline LB & $.95 * *$ & $.95 * *$ & $.98 * *$ \\
\hline DB & $.96 * *$ & $.94 * *$ & $.72 *$ \\
\hline Pooled & $.99 * *$ & $.97 * *$ & $.94 * *$ \\
\hline
\end{tabular}

${ }^{*} p<.05 \quad{ }^{* *} p<.001$

Table 2

Slope Values of the Regression Lines Obtained for Each Measure for Individual Birds

\begin{tabular}{|c|c|c|c|}
\hline \multirow[b]{2}{*}{ Bird } & \multicolumn{3}{|c|}{ Evoked Response Measure* } \\
\hline & $a-b$ & $\mathrm{~b}-\mathrm{c}$ & $c-d$ \\
\hline $\mathrm{Y}$ & .188 & .292 & .223 \\
\hline B & .125 & .152 & .077 \\
\hline LB & .269 & .234 & .173 \\
\hline DB & .220 & .286 & .134 \\
\hline Pooled & .200 & .241 & .151 \\
\hline
\end{tabular}

*All values are in microvolts/decibel.

Table 3

Amplitude Comparison of Evoked Responses Collected in Block 1 and Block 4

\begin{tabular}{cccc}
\hline & \multicolumn{3}{c}{ Evoked Response Measure* } \\
\cline { 2 - 4 } Bird & $\mathrm{a}-\mathrm{b}$ & $\mathrm{b}-\mathrm{c}$ & $\mathrm{c}-\mathrm{d}$ \\
\hline Block 1 & & & \\
Y & 11.6 & 18.6 & 8.8 \\
B & 10.1 & 13.3 & 6.6 \\
LB & 9.4 & 8.1 & 4.4 \\
DB & 10.2 & 14.2 & 14.0 \\
Mean & 10.3 & 13.5 & 8.5 \\
SD & .92 & 4.3 & 4.1 \\
Block 4 & & & \\
Y & 10.1 & 15.1 & 8.2 \\
B & 10.2 & 14.0 & 9.6 \\
LB & 12.9 & 10.8 & 5.2 \\
DB & 10.1 & 14.0 & 9.4 \\
Mean & 10.8 & 13.5 & 8.1 \\
SD & 1.4 & 1.9 & 2.0 \\
t & .47 & -.06 & -.22 \\
\hline
\end{tabular}

*All values are in microvolts. 


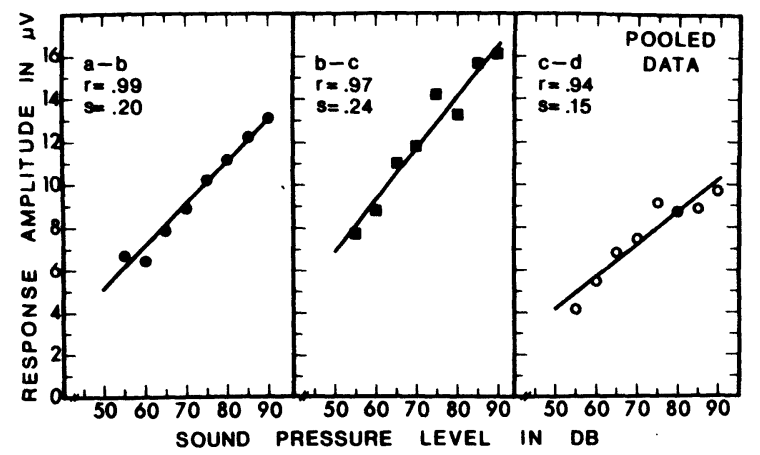

Figure 3.: Pooled amplitude-intensity functions for all four birds. Each data point is the mean obtained when the data from all four birds were grouped together. A single data point represents 4,000 stimulus presentations $(250 \times 4$ blocks $\times 4$ birds). Sound pressure level is in decibels (dB) re $20 \mathrm{microN} / \mathrm{m}^{2}$.

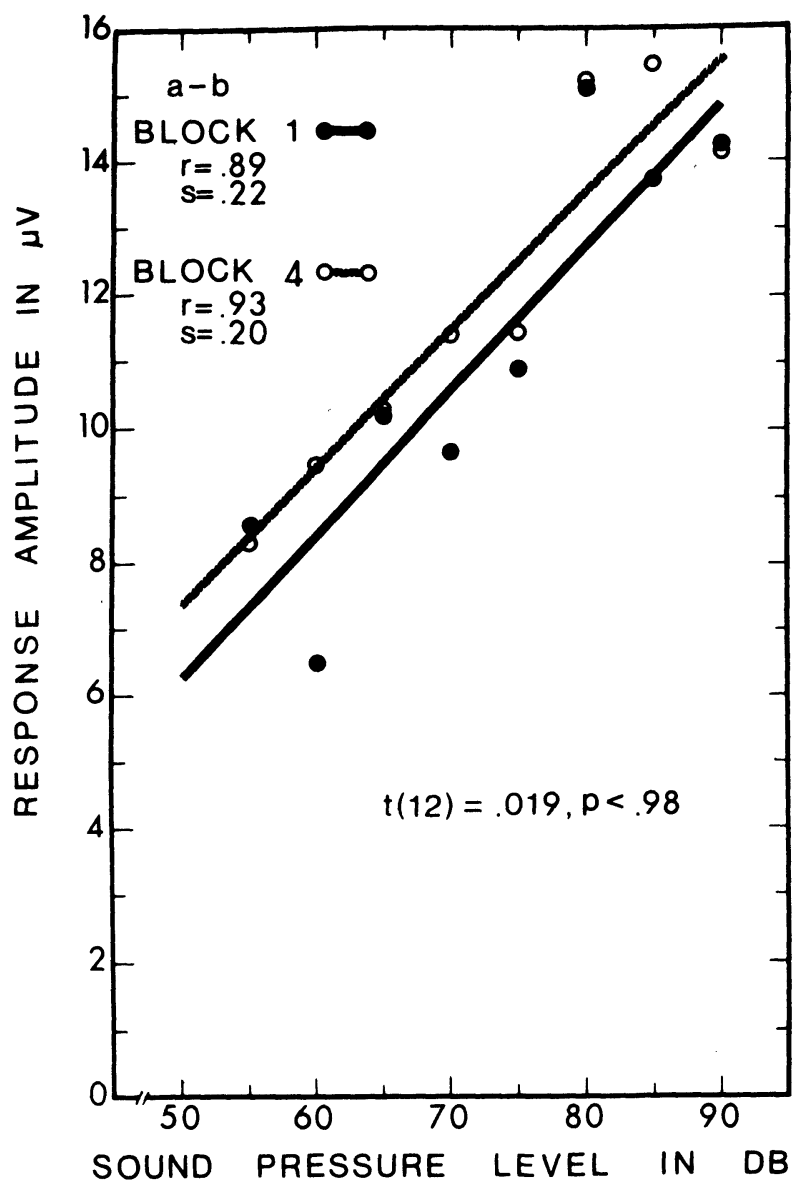

Figure 4. A comparison of evoked responses collected in Block 1 with evoked responses collected in Block 4. The data points for each block are means obtained when the data from all four birds for that block were grouped together. Each data point, then, represents 1,000 stimulus presentations $(250 \times 1$ block $\times 4$ birds). Sound pressure level is in decibels (dB) re $20 \mathrm{microN} / \mathrm{m}^{2}$.

fitted with regression lines. These were compared to similar data from Block 4 and revealed no significant difference in slope (McNemar, 1966) for any of the three amplitude measures between Block 1 and Block 4 . An example of this comparison for component $a-b$ is shown in Figure 4. For each measure, $a-b, b-c$, and $c-d$, these values are: $\mathrm{t}(12)=.019, \mathrm{p}<.99 ; \mathrm{t}(12)=.064$, $\mathrm{p}<.94$; and $\mathrm{t}(12)=.094, \mathrm{p}<.88$, respectively.

\section{DISCUSSION}

Our data clearly demonstrate a log-linear relationship between stimulus intensity and auditory evoked response amplitude over the intensity range examined. This relation has often been demonstrated for humans and other mammals (see as examples, reports by Davis, Bowers, \& Hirsh, 1968; Rothman, 1970; Tepas, Boxerman, \& Anch, 1972). This parallel is somewhat interesting in that birds and mammals have followed separate lines of evolution for almost 200 million years resulting in auditory systems that are quite dissimilar from one another. These differences have been previously described in terms of the peripheral (Schwartzkopff, 1973a; Takasaka \& Smith, 1971) and central (Boord, 1969; Karten, 1967, 1968) nervous system anatomy and also in terms of electrophysiological recordings of cochlear potentials (Schwartzkopff, 1973b).

There are certain limitations to scalp recording procedures such as the inability to determine where the response is generated. Nevertheless, by sheer proximity, it seems reasonable to assume that the parakeet evoked responses we report are related to activity in highest centers in the avian auditory system-the "Field L" in the neostriatum. If this is so, the similarities between avian and mammalian evoked responses may be even more remarkable.

The neostriatum is large and well developed in birds and covered with only a thin layer of poorly developed cortex. This is in contrast to the situation in mammals in which the striatum becomes a deep structure within the hemisphere because of the tremendous development of the neocortex and corpus callosum (Sarnat \& Netsky, 1974).

While all three amplitude measures show high positive correlations with intensity, the slopes and amplitudes associated with each component vary considerably. This fact may be relevant to those studies attempting to show a relation between evoked response measures of absolute sensitivity and psychophysical measures of absolute sensitivity. However, the three measures do not yield statistically different $\mathrm{x}$ intercepts, and furthermore, when the data for each measure are transposed to a ratio scale (i.e., percent response to $90 \mathrm{~dB}$ SPL), the resulting regression equations are not statistically different. ${ }^{1}$

The absolute threshold of the parakeet ear at $1,000 \mathrm{~Hz}$ has been determined by behavioral audiometry to be about $10 \mathrm{~dB}$ SPL (re $20 \mathrm{microN} / \mathrm{m}^{2}$ )(Dooling \& Saunders, 1975). The $\mathrm{x}$ intercept of the regression lines for components $a-b, b-c$, and $c-d$, for the four birds in this study is $24.9 \mathrm{~dB}, 21.4 \mathrm{~dB}$, and $22.7 \mathrm{~dB}$, respectively. This suggests that fitting regression lines to any or all of 
the evoked response waveform measures may be a reliable method for obtaining quick estimates of auditory sensitivity. The 10-15-dB difference between evoked response estimates of auditory sensitivity and corresponding psychophysical measures has been observed before by other investigators using different threshold criteria (Henderson, Hamernik, Woodford, Sitler, \& Salvi, 1973). These differences between evoked response estimates and psychophysical estimates of absolute threshold are usually attributed to the temporal integration of acoustic power occurring with the longer signals used in behavioral audiometric testing (Henderson et al., 1969).

The selection of the experimental parameters used in these experiments represents a compromise between, among other things, keeping an unanesthetized animal quiet for a long enough period of time, averaging a large number of EEG responses to improve the signal-to-noise ratio, and keeping the data collection time as short as possible. Clearly, the most difficult of these problems involved in keeping the animal quiet enough to collect reasonably artifact-free recordings. The decision to use a relatively fast repetition rate $(1 / 320 \mathrm{msec})$ and collect all the data for one animal in a single night was based on the observation that: (1) the birds appeared to be much quieter the first night in the testing chamber than on subsequent nights, and (2) slow rates of stimulus presentation (i.e., 1/2.0 sec), while giving somewhat greater amplitude responses, also resulted in considerably more movement, often completely obliterating the averaged evoked response.

Lastly, we feel that both the log-linear relation between stimulus intensity and evoked response amplitude and the demonstration of a similarity between evoked response estimates of auditory sensitivity and corresponding psychophysical measures are real. However, the exact nature of these relations is dependent on: (1) the averaging of a large number of EEG samples and (2) the repeated testing of individual subjects. The results of this study suggest that it would be fruitful to extend this procedure to other frequencies within the parakeet's range of hearing to determine the reliability of this approach for estimating absolute auditory sensitivity across frequencies.

\section{REFERENCES}

Biederman-Thorson, M. Auditory evoked responses in the cerebrum (Field $L$ ) and the ovoid nucleus of the ring dove. Brain Research, 1970, 24, 235-245. (a)

Biederman-Thorson, M. Auditory responses of units in the ovoid nucleus and cerebrum (Field $L$ ) of the ring dove. Brain Research, 1970, 24, 247-256. (b)

Boord, $R$. The anatomy of the avian auditory system. Annals of the New York Academy of Sciences, 1969, 68, 186-198.

Davis, H., Bowers, C., \& Hirsh, S. Relations of the human vertex potential to acoustic input: Loudness and masking. Journal of the Acoustical Society of America, 1968, 43, 431-438.

Dooling, R., Mulligan, J., \& Miller, J. Auditory sensitivity and song spectrum of the common canary (Serinus canarius). Journal of the Acoustical Society of America, 1971, 50, 700-709.

Dooling, R., \& Saunders, J. Hearing in the parakeet (Melopsittacus undulatus); Absolute thresholds, critical ratios, frequency difference limens, and vocalizations. Journal of Comparative and Physiological Psy chology, 1975, 88, 1-20.

Dooling, R., \& Walsh, J. A technique for continuous EEG recording in the awake parakeet. Behavior Research \& Instrumentation, $1974,6,545-546$.

Harman, A., \& Phillips, R. Responses in the avian midbrain, thalamus, and forebrain evoked by click stimuli. Experimental Neurology, 1967, 18, 276-286.

Harrison, J., \& Furumoto, L. Pigeon audiograms: Comparison of evoked potential and behavioral thresholds in individual birds. Journal of Auditory Research, 1971, 11, 33-42.

Henderson, D., Hamernik, R., Woodford, C., Sitler, R., \& Salvi, $R$. The evoked response audibility curve of the chinchilla. Journal of the Acoustical Society of America, 1973, 54, 1099-1101.

Henderson, D., Onishi, S., Eldredge, D., \& Davis, H. A comparison of chinchilla evoked response and behavioral thresholds. Perception \& Psychophysics, 1969, 5, 41-45.

Karten, H. The organization of the ascending auditory pathway in the pigeon (Columba livia) I. Diencephalic projections of the inferior colliculus (nucleus mesencephalic lateralis pars dorsalis). Brain Research, 1967, 6, 409-427.

Karten, H. The ascending auditory pathway in the pigeon (Columba Livia). II. Telencephalic projections of the nuclei ovoidalis thalami. Brain Research, 1968, 11, 134-153.

McNemar, Q. Psychological Statistics. New York: Wiley, 1966.

Ookawa, T \& Gotoh, J. Electroencephalogram of the chicken recorded from the skull under various conditions. Journal of Comparative Neurology, 1965, 124, 1-14.

Rothenberg, S., \& Davis, H. Auditory evoked response in chinchillas: Application of animal audiometry. Perception \& Psychophysics, 1967, 2, 443-447.

Rothman $H$. Effects of high frequencies and intersubject variability on the auditory-evoked cortical response. Journal of the Acoustical Society of America, 1970, 47, 569-573.

Samson, H., \& Lavine, L. Effects of pentobarbital on the visual evoked response in the avian optic tectum. Physiology and Behavior, 1972, 8, 1193-1196.

Sarnat, H., \& Netsky, M. Evolution of the Nervous System. New York: Oxford University Press, 1974.

Saunders, J., Gates, G., \& Coles, R. Brainstem evoked responses as an index of hearing thresholds in one-day-old chicks and ducklings. Journal of Comparative and Physiological Psychology, 1974, 86, 426-431.

Schwartzkopff, J. Structure and function of the ear and of the auditory brain areas in birds. In: A. V. S. DeReuck and Julie Knight (Eds.), Hearing mechanisms in vertebrates. Boston: Little, Brown, 1968. Pp. 41-63.

Schwartzkopff, J. Mechanoreception. In: D. S. Farner, J. R. King, and K. C. Parkes (Eds.), Avian biology, III. New York: Academic Press, 1973, 417-447. (a)

Schwartzkopff, J. Inner ear potentials in lower vertebrates: Dependence on metabolism. In: A. R. M dller (Ed.), Basic mechanisms in hearing. New York: Academic Press, 1973. Pp. 423-452. (b)

Takasaka, T., \& Smith, C. A. The structure and innervation of the pigeon's basilar papilla. Journal of Ultrastructure Research, 1971, 35, 20-65.

Tepas, D. Computer analysis of the electroencephalogram: Evoking, promoting, and provoking. Behavior Research Methods \& Instrumentation, 1974, 6, 95-110.

Tepas, D. Boxerman, L., \& Anch, M. Auditory evoked brain responses: Intensity functions from bipolar human scalp recordings. Perception \& Psychophysics, 1972, 11, 217-221.

Tepas, D., Guiteras, V., \& Klingaman, R. Variability of the human averaged evoked brain response to visual stimuli: A warning! Electroencephalography and Clinical Neuroph ysiology, 1974, 36, 533-537.

Tepas, D., Kress, G., \& Klingaman, R. APE: Average potential evaluation software for the Lab-8 system. Behavior Research Methods \& Instrumentation, in press, 1975.

Van Twyver, H., \& Allison, T. A polygraphic and behavioral study of sleep in the pigeon. Experimental Neurology, 1972, 35, 138-153.

\section{NOTE}

1. In this regard, it has been pointed out that each evoked response measure can be considered to carry the same information with regard to stimulus intensity. Furthermore, measure $b-c$ may be considered more appropriate in the sense that the largest amplitude change occurs with this measure, thus tending to reduce measurement error.

(Received for publication November 5, 1974; revision accepted January 30,1975 .) 